\title{
Physiological and Whitening Effects of Morus alba Extracts
}

\author{
Kyungmee Gug ${ }^{\dagger}$
}

\begin{abstract}
Mulberry extracts can be incorporated into skin-whitening products. The compound attributed to lighten the skin is arbutin, a form of hydroquinone that inhibits melanin release by suppressing the tyrosinase enzyme. For the cosmetic applications, the physiological effects of mulberry (Morus alba) extracts were investigated. The water soluble fraction of mulberry contains higher amount of protein (16.28 4.47\%) in contrast to fat (1.55 1.41\%). In addition, the fraction abundantly contains succinic acid $(972.4-275.8 \mathrm{mg} / \mathrm{g})$ and phosphoric acid $(1,628.4-121.9 \mathrm{mg} / \mathrm{g})$ in different parts of mulberry. The free radical scavenging ability in water soluble fraction was found to display remarkable effects in comparison with methanol and ethyl acetate fraction. The ethyl acetate-soluble of root and leaf showed remarkable tyrosinase inhibition activity by IC $50(\mu \mathrm{g} / \mathrm{ml})$. The anticancer activity of methanol fraction obtained from mulberry using human cancer cell lines showed growth inhibition effect $(270.14 \mathrm{mg} / \mathrm{ml}$ in Calu-6 cells, $295.29 \mathrm{mg} / \mathrm{ml}$ in HCT-116, and $332.29 \mathrm{mg} / \mathrm{ml}$ in MCF-7 cells, respectively). Based on the results, Morus alba extracts include cosmetic ingredients with antioxidizing and whitening properties.
\end{abstract}

Key words : Morus alba, Organic Acid, Antioxidant, Tyrosinase, MTT, Anticancer Activity, Whitening Property

\section{Introduction}

The Interests of the middle-aged in healthy skin have been increased under the influence of social trend of pursuing healthy beautiful appearance. In particular, various methods including chemical, physical, and biological means are being researched in order to improve the aging skin. Active oxygens are always generated during our respiration process to obtain necessary energy for keeping our health. The active oxygens are very harmful for our skin cells, leading to the pigmentation, wrinkles, and elasticity decrease on skin $^{[1,2]}$. As the results, active oxygens suppress the metabolism of our skins, results in the increased formation of melanin pigments which is the defense mechanism for protecting our skins. Although melanin produced in the skin protects skin from UV light, too much melanins leave dark brown stains ${ }^{[3]}$. Such stain formation on skin is not good for beauty culture. It

Department of Cosmetology Beauty Graduate School, Nambu University, Gwangju 506-706, Korea

†Corresponding author : gug1206@naver.com

(Received: October 31, 2012, Revised : March 25, 2012, Accepted : March 27, 2012) was reported from the in-vivo studies that second metabolic products originated from plants suppress the formation of free radical species and active oxygens, preventing oxidative cell loss ${ }^{[4,5]}$. Kojic acid and arbutin currently used for the inhibitor of tyrosinase show the unwanted side effects such as cytotoxicity and mutation. ${ }^{[6]}$. Thus, the development of novel safe materials with high whitening activity ${ }^{[7-10]}$.

Mulberry is widely distributed thru east asian countries including Japan, China (in particular, Manchu area), Mongolia. Mulberry leaves are widely used for silk-farming. leaves, fruits, branches, root barks of mulberry are also used for producing Chinese medicine to lower blood sugar (by $\gamma$-GABA) and blood pressure (by $\mathrm{DNJ}$ (deoxino-jirimicin) ${ }^{[11,13]}$. Mulberry contains inorganics (such as $\mathrm{Ca}, \mathrm{Fe}, \mathrm{K}, \mathrm{Zn}, \mathrm{Mg}$ ), vitamins (A, B, C), and vegetable fibers ${ }^{[12]}$. The cultivation of mulberry is relatively easy and simple thru the well-established mechanized farming technology. Thus, mulberry is the plant resources of global competitive power.

Here we report a study on the development of possible natural antioxidant and functional cosmetics by measuring the antioxidant and whitening effect of leaves, branches, root barks, and fruits of mulberry. 


\section{Materials and Methods}

\subsection{Preparation of Extract Samples}

The leaves, branches, roots, fruits of mulberry used for the research were given by Dongeuinara, Inc.. The mulberry materials were washed with distilled water and then dried in the shaded area. The mulberry materials were extracted with water. $10 \%(\mathrm{~g} / \mathrm{l})$ water extracts were subject to fractionation with methanol, hexane, ethyl acetate solvents, in order, to give extracts. The fractionated extracts were subject to centrifugation with a speed of 12,000 rpm for $30 \mathrm{~min}$ and were then filtered thru Whatman No. 4 filter paper. The resulting solutions were condensed by a rotary evaporator (EYELA N-N series) and finally freeze-dried to give powder samples.

\subsection{Analyses of General Components}

The analysis of general components of the samples were performed according to AOAC method ${ }^{[14]}$. The ash content for rough ash was determined when no weight change was observed after heating at $550^{\circ} \mathrm{C}$. The protein content for rough protein was determined after complete decomposition using sulfuric acid and decomposition promoter at heating condition. The volatile compounds were collected by using distillation setup and nitrogen content then was measured. The nitrogen content was converted to protein content by using protein coefficient. Rough lipid was extracted using a Soxhlet setup (Soxtex 2050 Auto Extraction Unit, Foss Teccater., Hillerod, Demnark) to give lipid. The amount of lipid was weighted to determine rough lipid content. Rough fiber content was measured by using the modified Henneberg-Stohman method. Vitamin C was extracted with 5\% metaphosphoric acid and then reacted with DNP (2,4-dinitrophenyl hydrazine) to be subject to colorimetric method (measuring absorbance at $520 \mathrm{~nm}$ ).

\subsection{Analysis of Organic Acids}

Organic acids were analyzed according to Lee method $^{[15]}$. The 3 gram sample was dissolved in $100 \mathrm{~mL}$ of distilled water and was subject to centrifugation at $4^{\circ} \mathrm{C}$ and $15,000 \mathrm{rpm}$. The above layered solution was filtered thru a Whatman No. 2 filter paper. The filtered solution was refiltered thru a $0.45 \mu \mathrm{m}$ membrane filter. The refiltered solution was purified using Sep-pak $\mathrm{C}_{18}$ cartridge and was finally analyzed by ion chromatogra- phy. For the ion chromatography a column [ICEAS6 $(9 \times 250 \mathrm{~nm})], 0.4 \mathrm{mM}$ heptafluorobutyric acid as a mobile phase, $5 \mathrm{mM}$ tetrabutylammonium hydroxide as a regenerator, an Electro conductivity detector, and nICE micromembrane as a blocking equipment were used at a moving speed of $1 \mathrm{ml} / \mathrm{min}$. Organic acid standards include acetic acid, butyric acid, citric acid, formic acid, lactic acid, malic acid, succinic acid, phosphoric acid, propionic acid, pyroglutamic acid, tartaric acid (Sigma Chemical Co., St. Louis, MO, USA).

\subsection{Measurement of Electron-donating Ability}

The electron donating ability of the extracts was determined by adapting Chu method ${ }^{[16]}$. The $50 \mu$ of $2 \times 10^{-4} \mathrm{M}$ DPPH (1,1-diphenyl-2-picrylhydrazyl, Sigma Chemical Co., St. Louis, MO, USA) solution was added to each $100 \mu \mathrm{l}$ samples, was well mixed for $10 \mathrm{sec}$, and then let it be alone at ambient temperature for $10 \mathrm{~min}$. The absorbance was measured at $517 \mathrm{~nm}$ using a UV spectrophotometer. The radical elimination ability of DPPH was obtained by expressing the percent between a sample and a control.

Free radical scavenging activity $(\%)=$

$$
\left(1-\frac{\text { Absorbance of control at } 517 \mathrm{~nm}}{\text { Absorbance of sample at } 517 \mathrm{~nm}} \times 100\right)
$$

\subsection{Measurement of Tyrosinase Suppressing} Activity

The suppressing effect of Tyrosinase was measured by dopachrome method ${ }^{[17]}$. $150 \mu$ l of mushroom tyrosinase $(110 \mathrm{U} / \mathrm{ml}$, Sigma Chemical Co., St. Louis, MO, USA), $225 \mu \mathrm{l}(2.5 \mu \mathrm{mM})$ of L-tyrosine, $225 \mu \mathrm{l}$ of 0.175 $\mathrm{M}$ phosphate buffer ( $\mathrm{pH}$ 6.8), and $300 \mu$ l ethanol solution or a sample solution $(1 \mathrm{mg} / \mathrm{ml})$ were well mixed. The solution was incubated at $37^{\circ} \mathrm{C}$ for $10 \mathrm{~min}$. Finally, DOPA chrome produced at $475 \mathrm{~nm}$ was measured. The suppressing degree of Tyrosinase was measured by using the following equation.

$$
\text { Tyrosinase inhibition }(\%)=\frac{A-B}{A} \times 100
$$

A is the absorbance of control reaction solution and $\mathrm{B}$ is the absorbance of reaction solution after adding a sample. In order to know the suppressing ability of tyrosinase the half concentration (to decrease initial tyrosinase activity to its half; $\mathrm{IC}_{50}$ ) and arbutin whitening 
material were obtained by using a standard curve and then compared.

\subsection{Anticancer Effect and Cell Toxicity Analysis}

The cell lines used for this research include Calu-6 (Human pulmonary carcinoma), MCF-7 (Human breast adenocarcinoma), and HCT-116 (Human colon carcinoma). 10\% FBS (fetal bovine serum, Gibco, Rocville, MD, USA) added RPMI 1640 medium was inoculated at $37^{\circ} \mathrm{C}$ and then incubated at a $5 \% \mathrm{CO}_{2}$ incubator. MTT assay was carried out to evaluate the cytotoxicity of mulberry methanol extract on cancer cell line ${ }^{[18]} .0 .1 \mathrm{~mL}$ $(105$ cells $/ \mathrm{mL})$ of cell suspension solution was inoculated at each well of 96 well plate, incubated at a $\mathrm{CO} 2$ incubator at $37^{\circ} \mathrm{C}$ for $24 \mathrm{hrs} .0 .1 \mathrm{~mL}$ of $0.3 \mathrm{mg} / \mathrm{mL}$ concentration of extract was added, cubated for $48 \mathrm{hrs}$, and upper layered solution was removed. $5 \mathrm{mg} / \mathrm{mL}$ concentration of MTT solution $(10 \mu \mathrm{L})$ was added to PBS (pH 7.4) and $90 \mu \mathrm{L}$ medium was then added. The mixture was injected to each well and then reacted for $3 \mathrm{hrs}$ in the dark. The upper layer was remived. DMSO solvent $(100 \mu \mathrm{L})$ was added and untouched for 10 minat ambient temperature. The absorbance was measured at 550 nm by using ELISA reader (ELx800, Bio-Tek, USA). The half concentration (to decrease initial cell growth to its half; $\mathrm{IC}_{50}$ ) and arbutin whitening material were obtained by using a standard curve and then compared.

\section{Results and Discussion}

\subsection{Content of Ingredients with Part of Mulberry}

The general component contents of rough ash, protein, lipid, fiber and vitamin $\mathrm{C}$ in the leaves, roots, branches, and fruits are in the range of $3.09 \sim 8.94 \%$ for rough ash, $4.47 \sim 16.28 \%$ for rough protein, $1.41 \sim 1.55 \%$ for rough lipid, and $3.52 \sim 43.21 \%$ for rough fiber.
Table 2. Contents of organic acid components in different parts of Morus alba $(\mathrm{mg} / 100 \mathrm{~g})$

\begin{tabular}{lcccc}
\hline \multirow{2}{*}{ Oranic acids } & \multicolumn{4}{c}{ Contents $^{\text {1) }}$} \\
\cline { 2 - 5 } & Leaf & Root & Branch & Fruit \\
\hline Citric & 7.1 & 394.2 & 39.2 & $3,529.4$ \\
Phosphoric & 460.6 & 121.9 & 230.2 & $1,628.4$ \\
Succinic & 972.4 & 623.6 & 275.8 & 494.6 \\
Acetic & 88.0 & 68.7 & 58.7 & 26.9 \\
Lactic & 55.4 & 24.5 & 130.4 & 18.4 \\
Tartaric & 84.0 & 12.4 & 44.9 & 95.1 \\
Malic & 33.8 & 56.0 & 11.1 & 44.3 \\
Formic & 10.9 & 6.8 & 16.9 & 6.3 \\
Pyroglutamic & $-2)$ & 35.6 & - & - \\
Butyric & 13.2 & - & - & - \\
Propionic & - & - & - & - \\
Total & 1725.4 & 1333.7 & 807.2 & 5843.4 \\
\hline
\end{tabular}

${ }^{1)}$ Mean \pm SD with different superscripts within a row is significantly different $(p<0.05)$ by Duncan's multiple range tests

${ }^{2)}$ Not detected

Although vitamin $\mathrm{C}$ was found to be $18 \mathrm{mg}$ per gram in the fruit, vitamin $\mathrm{C}$ was not found in leaves, roots, and branches of mulberry. Although the content of rough ash and protein was found to be greatest in leaves, the content of rough lipid was found to be similar in the all the regions of mulberry as seen in Table 1. The content of rough fiber in the branches was $43.21 \%$ and was greater by 12 times in the fruits.

\subsection{Analyses of Organic Acids}

Organic acids are the source of sour taste of fruit juice and important material for determining sugar and fragrance of fruits ${ }^{[19]}$. The organic acids contained in mulberry were given in Table 2. Among 11 standard

Table 1. Proximate compositions and vitamin C contents in different parts of Morus alba

\begin{tabular}{lcccc}
\hline \multirow{2}{*}{ Cmposition } & \multicolumn{4}{c}{ Contents } \\
\cline { 2 - 5 } & Leaf & Root & Branch & Fruit \\
\hline Crude ash (\%) & $8.94 \pm 0.11^{1)}$ & $3.55 \pm 0.15$ & $3.09 \pm 0.17$ & $3.82 \pm 0.17$ \\
Crude protein (\%) & $16.28 \pm 0.02$ & $11.87 \pm 0.15$ & $4.47 \pm 0.28$ & $6.78 \pm 0.70$ \\
Crude fat (\%) & $1.44 \pm 0.08$ & $1.55 \pm 0.06$ & $1.51 \pm 0.05$ & $1.41 \pm 0.05$ \\
Crude fiber (\%) & $10.78 \pm 1.40$ & $20.78 \pm 0.91$ & $43.21 \pm 0.68$ & $3.52 \pm 0.34$ \\
Vitamin C (mg/100 g) & $\operatorname{tr}^{2)}$ & $\operatorname{tr}$ & $\operatorname{tr}$ & $18 \mathrm{mg}$ \\
\hline
\end{tabular}

${ }^{1}$ Mean \pm SD with different superscripts within a row is significantly different $(\mathrm{p}<0.05)$ by Duncan's multiple ranges a test

${ }^{2)}$ tr represents trace. 
organic acids used for analysis, 10 organic acids (citric acid, phosphoric acid, succinic acid, acetic acid, lactic acid, tartaric acid, malic acid, formic acid, pyroglutamic acid, and butyric acid) were found at all the regions of mulberry. However, propionic acid was not detected at all the regions of mulberry.

In the leaves of mulberry total organic acid content was $1,725.4 \mathrm{mg} / 100 \mathrm{~g}$ and the content of succinic acid was greatest $(972.4 \mathrm{mg} / 100 \mathrm{~g})$. The content in the leaves then decrease in the order: phosphoric acid $>$ acetic acid $>$ tartaric acid $>$ lactic acid $>$ malic acid $>$ butyric acid $>$ formic acid $>$ citric acid. In the roots of mulberry total organic acid content was $1,333.7 \mathrm{mg} /$ $100 \mathrm{~g}$ and the content of succinic acid was greatest $(634.6 \mathrm{mg} / 100 \mathrm{~g})$. Next, the content in the leaves decrease in the order: citric acid $>$ phosphoric acid $>$ acetic acid $>$ malic acid $>$ pyroglutamic acid $>$ lactic acid $>$ tartaric acid $>$ formic acid. In the branches of mulberry total organic acid content was $807.2 \mathrm{mg} / 100 \mathrm{~g}$ and was smaller than the other regions of mulberry. The content of succinic acid was greatest $(275.8 \mathrm{mg} / 100 \mathrm{~g})$.
The content in the branches then decrease in the order: phosphoric acid $>$ lactic acid $>$ acetic acid $>$ tartaric acid $>$ citric acid $>$ formic acid $>$ malic acid. In the fruits of mulberry total organic acid content was $5,843.4 \mathrm{mg} /$ $100 \mathrm{~g}$ and the content of citric acid was greatest $(3,529.4$ $\mathrm{mg} / 100 \mathrm{~g}$ ). The content in the leaves then decrease in the order: phosphoric acid $>$ succinic acid $>$ tartaric acid $>$ malic acid $>$ acetic acid $>$ lactic acid $>$ formic acid. Among 10 organic acids citric acid, phosphoric acid, and succinic acid were found to be high content in all regions of mulberry. In the fruits of mulberry the content of citric acid was greater by 497 times than in the leaves. Citric acid is used as a fragrance additive for soft drinks and as a stabilizer for organic compounds. Phosphoric acid is used for additives for sour taste and fruit fragrance $^{[20]}$. However, Butyric acid was detected only in the leaves and pyroglutamic acid was found only in the roots.

\subsection{Measurement of Electron-donating Ability}

DPPH is a stable radical species and is used for

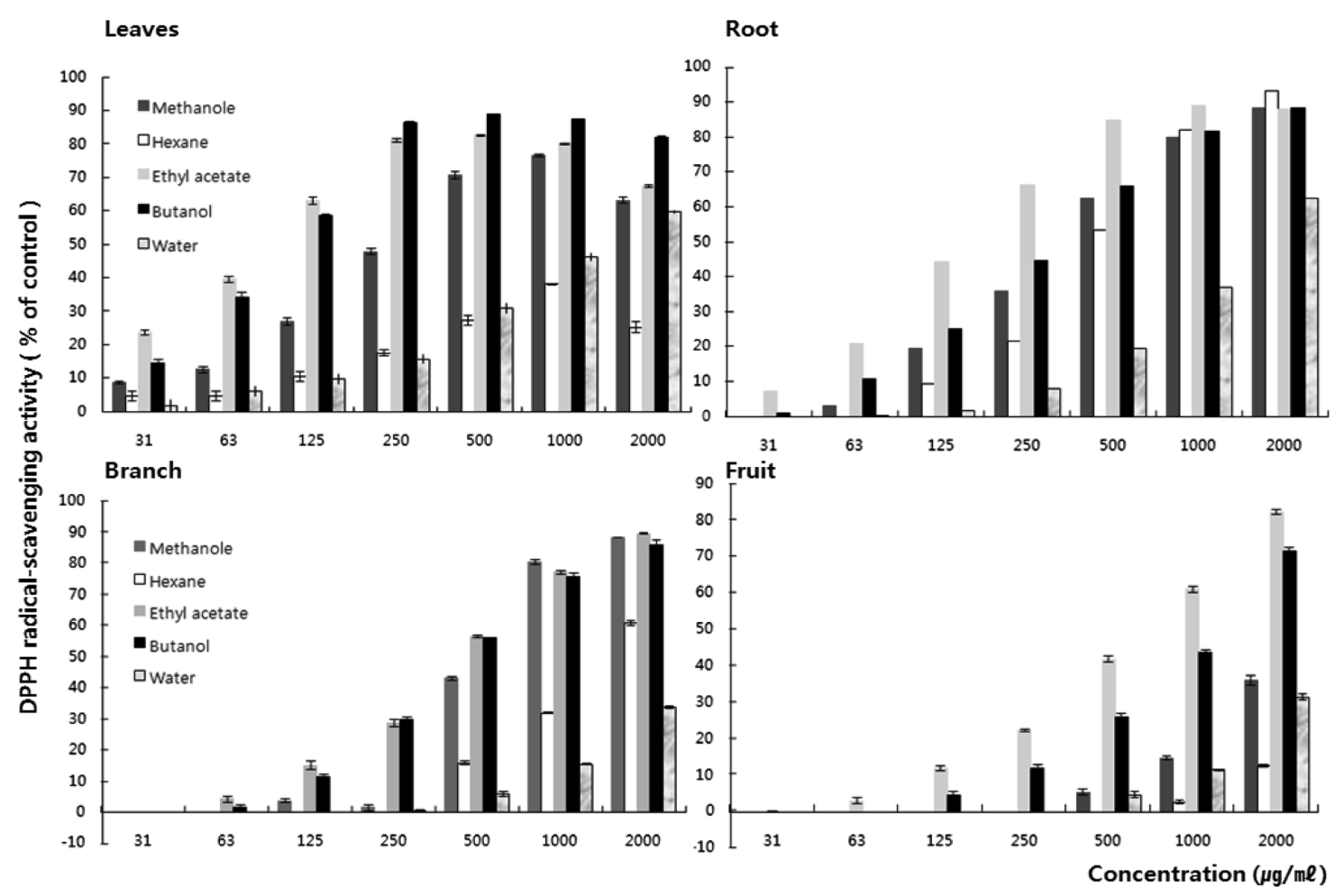

Fig. 1. Antioxidant activities of extracts and their fractions Morus alba part. DPPH radical scavenging activities of leaves, root, branch and fruit. 


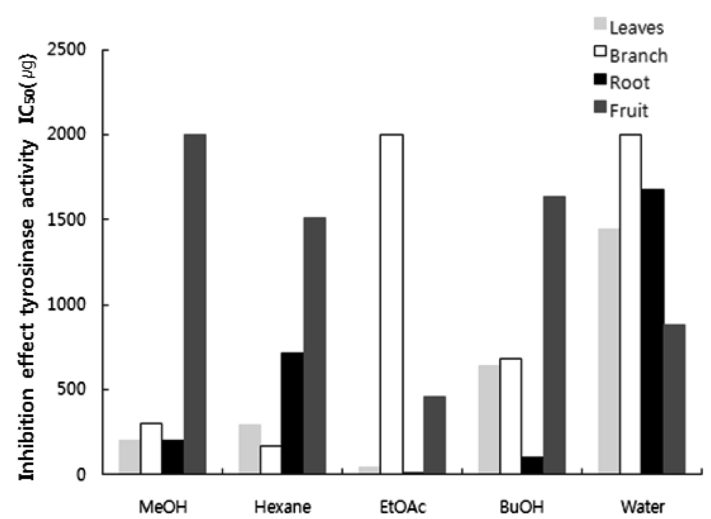

Fig. 2. Concentration required for selected tyrosinase inhibitors to reduce Morus alba part tyrosinase activity by $\mathrm{IC}_{50}$. Each value represents the mean of 3 separate experiments.

detecting the antioxidizing activity of antioxidants ${ }^{[21]}$. The antioxidizing activities of extracts (with hot water, methanol, hexane, ethyl acetate) in each region of mulberry were summarized in Fig. 1. The electron donating ability increased with increasing the extract concentration. The antioxidizing activity of ethyl acetate extract was greatest.

\subsection{Tyrosinase Suppressing Effect}

Tyrosine biosynthesis suppresser can suppress the synthesis of melanin polymer in the skin and can be used for the evaluation of whitening agent ${ }^{[25]}$. In the point of attaining $50 \%$ of the initial tyrosinase activity the fractionation concentration $\left(\mathrm{IC}_{50}\right)$ of mulberry with extracting solvent are given in Fig. 2. As seen in the experimental results, the greatest tyrosinase suppressing activity was obtained in the case of ethyl acetate fractionation.

\subsection{Anticancer Effect}

The growth suppressing effect on the cells (Calu-6, MCF-7, HCT-116) treated with methanol extract of mulberry was given in Fig. 3. For $\mathrm{IC}_{50}$, the cell growth activity of Calu- 6 cell was greatest to be $270.14 \mathrm{mg} / \mathrm{ml}$. The cell growth activities of MCF-7 cell and HCT-116 were found to be $295.29 \mathrm{mg} / \mathrm{ml}$ and $332.29 \mathrm{mg} / \mathrm{ml}$, respectively. Therefore, the extracts of mulberry (extracted with methanol) could be used as additives for drinks or tea. The cytotoxcity on NIH/3T3 cell was about $80 \%$ growth activity at $0.5 \mathrm{mg} / \mathrm{ml}$ (high concentration) ${ }^{[27]}$.

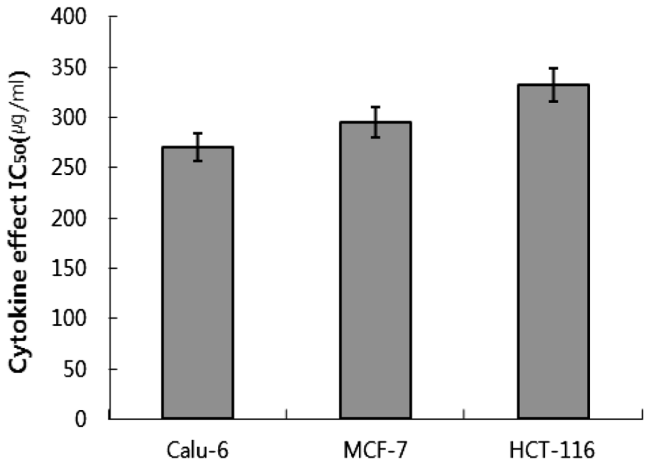

Fig. 3. Anticancer effect of methanol fraction from Morus alba extract on human cancer lines.

$\mathrm{IC}_{50}(\mu \mathrm{g} / \mathrm{ml})$ : Extract concentration which inhibits $50 \%$ growth of the cells

Calu-6: Human pulmonary carcinoma

MCF-7: Human breast,adenocarcinoma

HCT-116: Human colon carcinoma

Thus, the extracts of mulberry (extracted with methanol) could be used as additives for cosmetics.

\section{Conclusion}

In order to search chemicals which can be applied for cosmetic industry we investigated the extracts of Mulberry in terms of antioxidizing and whitening effects depending on the part and condition of extraction. From the hydrothermal extraction process of Mulberry 10 organic acids were detected along with several other components including proteins, cellulose, fats. Among the organic acids the content of citric acid, phosphoric acid, and succinic acid was higher than the other organic acids.

The compound attributed to lighten the skin is arbutin, a form of hydroquinone that inhibits melanin release by suppressing the tyrosinase enzyme. For the cosmetic applications, the physiological effects of mulberry (Morus alba) extracts were investigated. The water soluble fraction of mulberry contains higher amount of protein $(16.28 \sim 4.47 \%)$ in contrast to fat (1.55 1.41\%). In addition, the fraction abundantly contains succinic acid (972.4-275.8 mg/g) and phosphoric acid (1,628.4 $121.9 \mathrm{mg} / \mathrm{g}$ ) in different parts of mulberry. The free radical scavenging ability in water soluble fraction was found to display remarkable effects in comparison with methanol and ethyl acetate fraction. The ethyl acetatesoluble fractions of root and leaf showed remarkable 
tyrosinase inhibition activity by IC $50(\mu \mathrm{g} / \mathrm{ml})$. The anticancer activity of methanol fraction extracted from mulberry using human cancer cell lines showed growth inhibition effect ( $270.14 \mathrm{mg} / \mathrm{ml}$ in Calu-6 cells, $295.29 \mathrm{mg}$ / $\mathrm{ml}$ in HCT-116, and $332.29 \mathrm{mg} / \mathrm{ml}$ in MCF-7 cells, respectively). From the results above, Morus alba extracts include cosmetic ingredients with antioxidizing and whitening properties.

\section{Acknowledgments}

Mulberry extracts used for this research were kindly donated by Donguinara, Inc..

\section{References}

[1] S. O. Lee, M. J. Kim, D. K. Kim, and H. J. Choi, "Antioxidative activities of temperature-stepwise water extracts from lnonotus obliquns", J. Soc. Food Sci. Nutr., Vol. 34 No. 2, p. 139-147, 2005.

[2] R. Khairova , R. Pawar, G. Salvadore, M. F. Juruena, R. T. de Souse, M. G. Soeiro-de-Souza, M. Salvador, C. A. Zarate and W. F. Gattaz, "Machado-Viera R. Effects if lithium on oxidative stress parameters in healthy subjects", Mol. Med. Report, Vol. 5, No. 3, p. 680-682, 2012.

[3] S. M. Kim, I. Y. Song, M.K. Yang, and J.S. Jeong, "Dermatology", Hyunmoon, pp. 130-131, 2006.

[4] I. M. Chang, "Current Trend of Natural Products Industry and Utilization of Herbal Materials", Prospects for biofortification of grains by genetic engineeriong or plant breedin, pp. 28-37, 2002.

[5] S. Jayaram and S. M. Dharmesh, "Assessment of antioxidant potentials of free and bound phenolics of Hemidesmus indicus (L) R. Br against oxidative damage", Phamacognosy Res., Vol. 3, No. 4, pp. 225-31, 2011.

[6] C. L. Duncan and E. M. Foster, "Effect of sodium nitrite. sodium chloride. and sodium nitrate on germination and outgrowth of anaerobic spores", Appl. Microbiol., Vol. 16, No. 2, pp. 406-411, 1968.

[7] C. K. Ryu and M. K. Hwang, "Immune supression and stimulation of antioxidants 2- Effect of propyl gallate on Murine cell mediated Immune functions", Korean J. Food Hygiene, Vol. 5, No. 2, pp. 41-48, 1990.

[8] F. Rubio-Senent, G. Rodriguez-Gultierrez, A. LamaMonoz, and J. Ferandez-Bolanos, "New phenolic compounds hydrothemally extracted from the olive oil by-product Alperujo and their antioxidative activities", J. Agric. Food Chem., Vol. 60, No. 5, pp. 1175-86, 2012.

[9] M. Kim, J. Park, K. Song, H. G. Kim, J. S. Koh and Y. C. Boo, "Screening of plant extracts for human tyrosinase inhibiting effects", Int. J. Cosmet. Sci., Vol. 34, pp. 1468-2494, 2012.

[10] C. Chai, H. K. Ju, S. C. Kim, J. H. Park, J. Lim, S. W. Kwon and J. Lee, "Determination of bioactive compounds in fermented soybean products using GC/MS and further investigatation of correlation of their bioactivities", J. Chematogr. B Analyt. Technol. Biomed. Life Sci., Vol. 880, No. 1, pp. 42-49, 2012.

[11] E. B. Lee and O. K. Kim, "Antihyprtglycemic cinsituent of aralia elata root bark(I-II)", Korean J. Pharmacon., Vol. 24, pp. 213-222. 1993.

[12] Y. Yoshikumi, "Inhibition of intestinal $\alpha$-glycosidase activity ans postprandial hyperglycemia by moranoline and its N-alkyl derivative", Agric. Biol. Chem. Vol. 52, pp. 121-126, 1994.

[13] S. Y. Kim, W. C. Lee, A. J. Kim and S. K. Kim, "Antihyperlipidemic effects of methanol extracts from muberry leaves in cholesterol-induced hyperglycemia rats", J. Korean Soc. Food Sci. Nutr., Vol. 27, pp. 1217-1222, 1998.

[14] G. Y. Park, "Characterization of secondary metabolites in fermented pine extract", MS thesis, Dept. of Biotechnology, Chosun University, Gwangju, 2008

[15] E. H. Lee, "Changes in Physico-chemical characteristics of Buckwheat Sprouts during germination", MS Thesis, Dept. of Food and Nutrition, Sookmyung Women's University, Seoul, 2006.

[16] Y. H. Chu, C. L. Chang and H. F. Hsu, "Flavonoid content of several vegetables and their antioxidant activity", J. Sci. Food Agr., Vol. 80, pp. 561-566, 2000.

[17] J. Grayand and Jr. LR. Dugan, "Inhibition of N-Nitrosamine formation in model food system", J. Food Sci., Vol. 40, pp. 981-985, 1975

[18] Y. Athukorala, K. N. Kim and Y. J. Jeon, “Antiproliferative and antioxidant properties of an enzymatic hydrolysate from brown alga", Ecklonia cava. Food Chem. Toxicol., Vol. 44, pp. 1065-1074, 2006.

[19] Y. S. Do, H. J. Whang, J. E. Ku, and R. Y. Kwang, "Organic acids content of the selected Korean apple cultivars", Korean J. Food Sci. Technol., Vol. 37, No. 6, pp. 922-927, 2005.

[20] Y. J. Kong, B. K. Park and D. H. Oh, "Antimicrobial activity of Quercus mongolica leaf ethanol extract and organic acid against food-borme microorganisms", Korean J. Food Sci. Technol. Vol. 33, 
No. 2, pp. 178-183, 2001.

[21] H. Aoshima, H. Tsunoue, H. Koda and Y. Kiso, "Aging of whiskey increases 1,1-diphenyl-2-picrylhydrazyl radical scavenging activity", J. Agric. Food Chem., Vol. 52, pp. 5240-5244, 2004.

[22] J. S. Kim and S. Y. Choi, "Physicochemical properties and antioxidative activities of Omija(Schizandra chinensis Bailon)", Korean J. Food Nutr., Vol. 21, No. 1, pp. 35-42, 2008.

[23] S. A. Kang, M. S. Oh, D. R. Kim, J. U. Kang, W. N. Kim, M. S. Chang and S. K. Park, "Compositions of Astragali radix and Angelicae radix by DPPH radical scavenging activity", Korean J. Herbol., Vol. 21, pp. 17-24, 2006.

[24] B. J. An, J. M. Park, H. J. Bae, J. R. Pyun and M. A. Song, "Antioxidant and antibacterial effect of Korean Isodon japonicus, H”, J. Korean Soc. Appl.
Biol. Chem., Vol. 49, pp. 129-134, 2006.

[25] C. H. Kim, M. C. Kwon, J. G. Han, C. S. Na, H. G. Kwak, G. P. Choi, U. Y. Park and H. Y. Lee, "Skin-whitening and UV-protective effects of Angelica gigas nakai extract on ultra high pressure extraction process", Korean J. Medicinal Crop. Sci., Vol. 16, No. 4, pp. 255-260, 2008.

[26] J. H. Lee, J. H. Park, J. S. Lee and K. U. Whang, "The lnhibitory effects of Ramulus mori extract on melanogenesis of normal human melanocytes", Korean J. Investi. Dermato., Vol. 8, No. 2, pp. 8690, 2001.

[27] H. J. Jun, H. Y. Lee, J. D. Kim, M. Y. Heo and J. H. Lee, "Genotoxicity and mutagenicity of the extracts of Morus alba L", Korean J. Medicinal Crop. Sci., Vol. 13, No. 6, pp. 217-225, 2005. 